\title{
Interaction value formation spaces: configurations of practice-theory elements in service ecosystems
}

\author{
Per Echeverri \\ Department of Service Research Center, Karlstad University, Karlstad, Sweden
}

\begin{abstract}
Purpose - Contemporary service and marketing research on value co-creation and value co-destruction assume a one-dimensional view on value, ranging from positive value co-creation, alignment and high value to negative value co-destruction, misalignment and low value. This limitation has recently led researchers to conceptually develop more dynamic spatial-temporal models of how value is formed during the interaction, e.g. in terms of different relationships between practice elements (procedures, understandings and engagements) both within and between actors in "value formation spaces". However, much of this research awaits validation and is in need of more details. This study aims to address this limitation with the purpose of detailing how and why the mechanisms in such spaces are formed.

Design/methodology/approach - Two different and interlinked typologies were analytically derived from previous research and applied on ethnographically-inspired multi-perspective empirical data from a service combining health care and transport service ecosystems, using a combination of interviews, observations and service design methodologies. The design in combination with a practice theory perspective was used to articulate crucial aspects related to understanding the dynamics of value co-formation for elaborative and illustrative purposes.

Findings - The study contributes to service theory by conceptualizing as follows: a typology consisting of nine different configurations of practice elements (within and between such elements) and eight possible directions that value formation can take, suggesting a theory that explains value co-creation, value co-destruction and mixed cases.

Research limitations/implications - Although the findings have been developed in a specific empirical context, they articulate a conceptualization applicable to many other service and marketing value co-formation settings.

Practical implications - The typologies are conceptual tools to be used in identifying and measuring the alignment/misalignment of practice elements in complex organizations. The empirical findings uncover service problems faced by disabled customers.

Originality/value - The suggested typologies can guide research and practitioners in understanding and analysing value co-formation mechanisms in complex service settings.
\end{abstract}

Keywords Co-creation, Service encounter, Service systems, Qualitative research, Customer value, Frontline service employees, Interaction value formation, Value co-formation, Value co-creation, Value co-destruction, Practice theory, Practice elements, Vulnerable customers

Paper type Research paper

\section{Introduction}

Contemporary service and marketing research on value cocreation and value co-destruction assumes a onedimensional view of value co-formation, holding that at the one end of the dimension (the "positive" end) represent value co-creation, alignment of practices and high value/ well-being and at the other end (the "negative" end) we have value co-destruction, misalignment and low value/less wellbeing (McColl-Kennedy and Cheung, 2018; Vargo and Lusch, 2016). This limitation has recently led researchers to conceptually develop more dynamic spatial-temporal models of how value is co-formed during the interaction. Among the more dominant research streams addressing this

The current issue and full text archive of this journal is available on Emerald Insight at: https://www.emerald.com/insight/0887-6045.htm

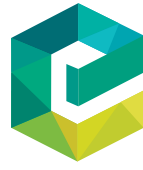

Journal of Services Marketing

35/9 (2021) 28-39

Emerald Publishing Limited [ISSN 0887-6045]

[DOI 10.1108/JSM-03-2021-0084] phenomenon in contemporary research of value co-creation and value co-destruction, we find service ecosystem theory, resource integration theory and practice theory (Echeverri and Skålén, 2021, for a recent review).

Each of these streams addresses slightly different aspects of this interactive value formation (IVF) and thus provides partly different answers as to why and how value is co-created and codestroyed. In the article, the term value co-formation is occasionally used as it denotes both the positive (creation) and negative (destruction) sides of this phenomenon. Service

\footnotetext{
(C) Per Echeverri. Published by Emerald Publishing Limited. This article is published under the Creative Commons Attribution (CC BY 4.0) licence. Anyone may reproduce, distribute, translate and create derivative works of this article (for both commercial and non-commercial purposes), subject to full attribution to the original publication and authors. The full terms of this licence may be seen at http://creativecommons.org/licences/by/4.0/ legalcode
}

Received 18 March 2021

Revised 10 June 2021

17 August 2021

19 August 2021

Accepted 22 August 2021 
ecosystem theory primarily addresses network characteristics (Beirão et al., 2017; Ng et al., 2018), typically zooming out to systemic, multi-actor relations, embedded multi-level structures and organizational arrangements. Contemporary service ecosystem research points to aspects such as configurational fit, worldview, self-adjustment, resilience, adaptation, integrated resources and shared value co-creation (Frow et al., 2019). In resource integration theory, different sets or composites of human and non-human capacities are addressed instead (Smith, 2013). Although having great merit, both these streams tend to overlook the inherent social and dynamic aspects of the core IVFing processes.

In comparison to service ecosystem and resource theory, recent advancements in practice-theory informed research in marketing (Schau et al., 2009), focusing on the phenomena of value co-creation and/or value co-destruction, have more clearly addressed this problem and suggested the concept of IVF (Camilleri and Neuhofer, 2017; Caridá et al., 2019; Echeverri and Skålén, 2011, 2021; Makkonen and Olkkonen, 2017) as a less normative term that includes not only value co-creation but also value co-destruction, and uncovers dynamic social interaction in spaces of value formation (Cabiddu et al., 2019; Crowther and Donlan, 2011). The term "spaces" denotes an undefined sphere in which value formation activities are undertaken. However, and according to a recent literature review (Echeverri and Skålén, 2021), frameworks addressing IVF lack any conceptualization of how processes, more specifically, can vary in such spaces, e.g. specifying the positions and movements of value co-formation processes in these imagined spaces. Echeverri and Skålén (2021) outline a conceptual framework of IVF and suggest how we can conceptualize this; however, this framework awaits validation and details.

This article addresses this shortcoming and seeks to conceptualize, based on practice theory (Reckwitz, 2002; Schatzki, 2002, 2019), the following two different typologies: configurations of the practice elements used in IVF and changes in the directions of these configurations in a twodimensional IVF space. Based on a literature review, it is argued that these two aspects are overlooked in contemporary service and marketing theory (Cabbidu, 2019; Caridá et al., 2019; Echeverri and Skålén, 2021). By means of this, the article contributes conceptually and theoretically to the notion of IVF spaces in a service ecosystem context to understand the specific ways actors realize both value co-creation and value codestruction, a recently-evolved research field in contemporary service and marketing.

Our analysis draws on a detailed empirical study of how different organizational actors experience different parts of combined transport-health-care service; a process that enables disabled patients to visit a hospital and receive medical care. A multi-actor approach identified a rather complex service system with crucial configurations of aligned (and misaligned) elements. The article partly draws on the recently suggested conceptual framework of IVF spaces (Echeverri and Skålén, 2021) in which two dimensions of alignment are identified -i.e. alignment within (AW) and alignment between (AB) elements of practices, jointly defining various value co-formation processes. The study further explores these two dimensions, as originally implied by Echeverri and Salomonson (2017), but not explored at length in service and marketing research. In addition, the article also explores and details how these different configurations form part of value co-creation and value codestruction or a mix thereof, as it reflect a wide range of valueforming directions. The article contributes to service and marketing theory in that it suggests two elaborated typologies, i.e. one for practice element configurations and one for valueforming directions, with both of these explaining why and how value is formed during the interaction.

\section{Literature review}

The contemporary marketing literature nurtures the idea of value in terms of being defined, uniquely and phenomenologically, by the beneficiaries of service ecosystems (Vargo and Lusch, 2016). It is argued that, for these actors (i.e. customers, employees and other stakeholders), value is experientially determined on the basis of the specificity of their contexts (Vargo, 2008) by means of the integration of human and non-human resources from many sources, including the possibility of customers co-creating their experiences autonomously (McColl-Kennedy et al., 2012). This view holds that value is formed at different levels across different interfaces (Teixeira et al., 2017), and coordinated by the institutions of the service ecosystems.

In contrast to this rather "zoomed-out" perspective on value co-formation in service ecosystem thinking, practice-theoryinformed approaches view value co-formation as an enactment of different practice elements, situated in material arrangements (Schatzki, 2002, 2019). Drawing on Korkman and Araujo (2019), it can be argued that resources are integrated into practices and that practices, in turn, define service ecosystems. This view articulates the main characteristics and locus of value co-formation, in terms of being intersubjective, interactional, contextual and realized in some way in a service ecosystem, but offers little on the details of how value co-formation is achieved. For example, it has not yet been outlined how to specify configurations of practice elements whilst these are being enacted or their interrelations, degree of alignment and function during value co-creation and value co-destruction.

In what follows, we briefly discuss three major and partly overlapping theoretical perspectives, suggested in the contemporary marketing literature, that have recently tried to address this shortcoming with varying results. We first discuss service ecosystem and institutional perspectives and then resource integration perspectives. We want to address that these two only to some degree can articulate a clear answer to how and why value is co-formed. Finally, we discuss recent advancement in practice theory perspectives that offers a somewhat alternative approach to deal with the limitations found in the former research perspectives. The study reported in this article, build on and add to this latter perspective in elaborating the dynamics of interaction value formation.

\section{Service ecosystem and institutional perspectives}

In service and marketing research, a growing amount of attention is being paid to the contexts of value formation, to better understand how value co-formation is achieved (Vargo and Lusch, 2016), with the concept of the service ecosystem having emerged as a way of understanding value formation 
dynamics (Vargo and Lusch, 2016), i.e. how social factors that are embedded in institutional structures ideally guide resource integration, coordinating the efficient distribution of resources in value co-creation (Akaka et al., 2012). According to Scott (2013), institutions are to varying degrees made up of the following three pillars: i.e. the normative pillar, which has to do with values and norms, the regulative pillar, which concerns formal rules and laws, and the cultural-cognitive pillar, which has to do with meanings and shared symbols. These are thought of in terms of coordinating people's actions.

A service ecosystem is thought of as relatively selfcontained in relation to other systems, due to different actors within that system dealing with separate, more or less, predefined and mutually-beneficial procedures. It is also thought of as relatively self-adjusting, to facilitate the ultimate objectives of a given service, and as being in a reciprocal relationship with coordinating and shared social structures or institutions (Vargo and Lusch, 2016). Although this "relativeness" of the service ecosystem is acknowledged, due to indicating the possibility of, for example, system interdependencies, and more importantly the possibility of value co-formation not being so selfadjusting, it actually points to the possibility of service ecosystems having limited systemic characteristics. It also points to the possibility of inherent system mechanisms that have the capacity to explain various value co-formation outcomes.

An ecosystem perspective can be highly explanatory as it can identify institutional structures that define and relate ecosystem elements, thus explaining, for example, why organizational routines on sub-levels are arranged in certain ways due to overarching objectives or why organizations sometimes fail to reach sub-level objectives (Giraldo, 2014; Vargo and Lusch, 2014, 2016).

However, the ecosystem perspective has its limitations as regard conceptualizing the inherent mechanisms of the actions that actors undertake whilst interacting. For a long time, institutional theorists have been seeking to overcome this problem by acknowledging the need to consider institutional structures as simultaneously externally institutionalized - e.g. as the authority, power, regulation - and internally present in professionals' minds, beliefs and practices, an idea reflected in contemporary value-formation research (Cova et al., 2019; Edvardsson et al., 2014; Hughes et al., 2018; Vargo and Lusch, 2016). However, neo-institutionalists have shown that professionals are also engaged in reflexive deliberations regarding individuals' own interests and projects in relation to or even apart from, institutional arrangements (Archer, 2003, 2007; Correia, 2016). Actions are enacted in organizations by individuals and collectives in everyday situations as a result of employees' embedded structural positions, also being dependent on social skills, however (Powell and Rerup, 2017; Suddaby et al., 2016; Correia, 2016).

To conclude, the ecosystem and institutional perspective in marketing can only to a limited degree uncover the mechanisms explaining the logic sustaining the course of action through which actors deliberate in relation to value co-formation circumstances (Archer, 2003, 2007). This perspective has difficulties conceptualizing how actors in service ecosystems interactively connect with other actors and link the available resource structures during value forming interactions (Mouzelis, 2010).

\section{Resource integration perspectives}

Whilst research acknowledges that value formation is located in the interactions between multiple linked actors sharing common goals (Plé, 2016; Plé and Cáceres, 2010; Smith, 2013; Tsiotsou, 2016; Vargo and Lusch, 2016), it also draws on the notion of resource integration, i.e. using knowledge and skills when operating on given resources (Vargo and Lusch, 2016). Resources can include having access to materials, esteem, time, sociality, motivation, the energization of behaviour, the power balance, goals, groupthink, trust, coordination, etc. (Prior et al., 2016; Smith, 2013). Resource-based perspectives are also found in research on value co-destruction. Plé and Cáceres (2010) contend that value can be co-destroyed due to the misuse of resources, i.e. failure to integrate and/or apply resources in a manner that is both appropriate for and expected by another service system or human being (Luo et al., 2019). Prior and Marcos-Cuevas (2016) conceptualize misuse in terms of resource misalignment whilst Vafeas et al. (2016) view it as suboptimal value realization.

Resource-based conceptualizations not only focus on sets of resources and antecedents when it comes to understanding value formation (Hiler et al., 2018; Zainuddin et al., 2017; Vafeas et al., 2016). There are also studies that try to uncover how resources come into being (Edvardsson et al., 2014), e.g. the mobilization of resources during social interaction (Cabbidu et al., 2019), and to explore them during matching and resourcing (Caridá et al., 2019). Such approaches address the processual side of value co-formation but experience difficulties articulating the dynamic social mechanisms inherent in the collaborative nature of IVF (Echeverri and Skålén, 2021).

\section{Practice-theory perspectives}

Recently, we have seen a growing stream of practice-theoryoriented research in marketing, drawing on the well-established idea of using practices as a relevant unit of analysis when it comes to understanding and explaining human activity (Nicolini, 2012; Schatzki, 2019). Practice-theory perspectives are also used in research on value co-formation.

Working in the practice-theory tradition, several marketing researchers draw on Schatzki (2002) and Schau et al. (2009) and argue that practices are relatively routinized actions that people perform, consisting of elements such as procedures, understandings and engagements. Procedures represent rules and procedural schemes among actors, a form of know-what, i.e. explicit formulations, principles, precepts and instructions that enjoin, direct or remonstrate people to perform specific actions. Understandings represent practical knowledge or skills among interactants, a kind of know-how. Engagements represents teleo-affective structures, i.e. a range of normativized and hierarchically ordered ends, projects and tasks, a kind of motivations and emotions (Schatzki, 2019). In a practice-theory perspective, value co-formation in service and marketing contexts is realized in a reciprocal relationship between congruence and incongruence, or the alignment and misalignment, of practice elements (Daunt and Harris, 2014; Echeverri and Skålén, 2011; Hasche and Linton, 2018; Hiler 
et al., 2018; Prior and Marcos-Cuevas, 2016; Skålén et al., 2015; Smith, 2013). In line with this view, and drawing on the work of Crowther and Donlan (2011), Cabiddu et al. (2019) elaborate on the notion of value variation spaces and suggest that value is formed in a "space", somewhere and somehow. Echeverri and Salomonsson (2017a), as do Shove et al. (2012), suggest that value co-formation is determined by alignment/misalignment not only "within" elements of practices but also "between" elements of practices. This is an important conceptual difference in relation to the implicit one-dimensional value concept suggested in the initial work on value co-creation and codestruction research (Echeverri and Skålén, 2011; Plé and Cáceres, 2010). However, this notion of a two-dimensional value space has not yet been elaborated on empirically in service and marketing research, although it may have the potential to explain more of the details of value co-formation.

In a recent study, Echeverri and Skålén (2021) suggest a conceptual framework of the IVF space. Key concepts of the IVF space framework include the alignment/misalignment of practice elements (procedures, understandings and engagement), both within and in-between practice elements. The term "within" denotes the degree to which specific practice elements are aligned between the actors involved, e.g. shared/ not shared procedure knowledge (know-what), whilst the term "between" denotes the degree to which the set of different practice elements of each actor involved are aligned, e.g. between the actors' procedure knowledge and practical skills (know-what and know-how), a conceptual difference suggested in Echeverri and Salomonson (2017).

An example taken from the health care context may illustrate this: When a patient and a nurse greet each other in a way that both enjoy and view as appropriate, there is a high degree of AW shared practice elements (e.g. both actors sharing the "know-how" of performing this greeting). If not, the elements are misaligned. However, if one of the actors, for example, the nurse, assumed as having knowledge of what is appropriate, forgets the greeting, or performs it in an impolite or off-hand manner, then the $\mathrm{AB}$ the practice elements, on the part of the nurse, (i.e. "know-what" and "know-how", as well as his/her emotional commitment) will to a certain degree not be aligned.

\section{Analytical framework}

Aligned with the theoretical conceptualizations of Echeverri and Skålén (2021), it is possible to analytically derive different forms of enactment of practice elements, covering both value co-creation and value co-destruction. The following four extreme combinations of the alignment/misalignment of practices can be derived: Total AW and between (High/High); Total misalignment within (MW) and between (Low/Low); Total AW but total misalignment between (MB) (High/Low) and; Total MW but total AB (Low/High). In real life, however, the enactment of practices consists of variations somewhere within the space between these extremes, closer to any of the extremes identified in Figure 1, e.g. towards the upper right, lower left, upper left or lower right. In the figure, the four quadrants are indicated with dotted lines to illustrate the spheres in which potential cases may be positioned.

Different positions within the value co-formation space do not display an objectively right or wrong enactment of practice elements, rather an intersubjective (sometimes only subjective, e.g. individual web shopping) and relativistic preference experience (Holbrook, 2006), as the value variation space displays differences in AW and between the practice elements, the mechanism behind the different forms of value coformation. In real life, actors may have somewhat divergent views of what shapes value, being able to position an encounter slightly differently. Further, the positions within the value coformation space do not show whether one actor is more valueforming than another, as they only display different configurations in a given situation. In empirical analyses of what is of value to the actors, multiple actor perspectives are typically relevant. How many, and which, perspectives to include to define the actual value of a given service system is an empirical question. In the marketing discourse, the customer often has primacy. In other situations, such as when the aim is to identify the total value of a service ecosystem (in relation to other ecosystems), other actors' views, even from outside the system, may be relevant to include.

Based on the chosen practice theory approach, the analysis assumes three main types of practice elements (Schatzki, 2002, 2019; Schau et al., 2009), i.e. procedures (P), understandings (U) and engagement (E), that lead to the possibility of identifying different alignment/misalignment relations, as shown in what follows and in Table 1 . The first group of relations refers to AW/MW the three types of practice elements; i.e. comparing the specific elements of actor $A$ with actor $B$ (a dyad) with regard to: procedures $\left(\mathrm{P}_{\mathrm{A}^{-}}\right.$ $\left.P_{B}\right)$; understandings $\left(U_{A}-U_{B}\right)$; and, engagements $\left(E_{A}-E_{B}\right)$. The second group of relations refers to the alignment/MB elements on each respective side; i.e. actor A's proceduresunderstandings $\left(\mathrm{P}_{\mathrm{A}}-\mathrm{U}_{\mathrm{A}}\right)$; procedures-engagements $\left(\mathrm{P}_{\mathrm{A}}-\mathrm{E}_{\mathrm{A}}\right)$; understandings-engagements $\left(\mathrm{U}_{\mathrm{A}}-\mathrm{E}_{\mathrm{A}}\right)$; and actor $\mathrm{B}$ 's procedures-understandings $\quad\left(\mathrm{P}_{\mathrm{B}}-\mathrm{U}_{\mathrm{B}}\right)$; proceduresengagements $\left(\mathrm{P}_{\mathrm{B}}-\mathrm{E}_{\mathrm{B}}\right)$; understandings-engagements $\left(\mathrm{U}_{\mathrm{B}^{-}}\right.$ $\mathrm{E}_{\mathrm{B}}$ ). It is in these relations that we are able to identify variations regarding alignment/misalignment. In multi-actor settings, the complexities increase.

Along with the possibility of identifying configurations, it is also possible to identify typical changes in the directions of IVF (actual, implied or needed changes/movements). In what follows, typical forms are outlined. However, in real life, a wide range of combinations and intermediate forms can be identified. In Figure 1, typical directions are illustrated using a big dot (representing a "starting point"), with eight typical arrows in the space. Each direction is specified in Table 1 and the markers within parentheses and in the figure are used in the quotes.

To conclude, drawing on the notions of the value formation space, as elaborated in the IVF framework of Echeverri and Skålén (2021) and the analytical framework derived above, this article details the mechanisms of value formation used in service eco-systems, suggesting typologies of practice configurations and directions that actors may undertake in such a space. In doing so, it offers a response to the limitations, in terms of the ability to explain value coformation, identified in the literature reviewed, i.e. both service ecosystem/institutional conceptualizations and resource integration conceptualizations, as well as practicetheory conceptualizations. 
Figure 1 Analytical framework of value co-formation space depicting possible positions and directions

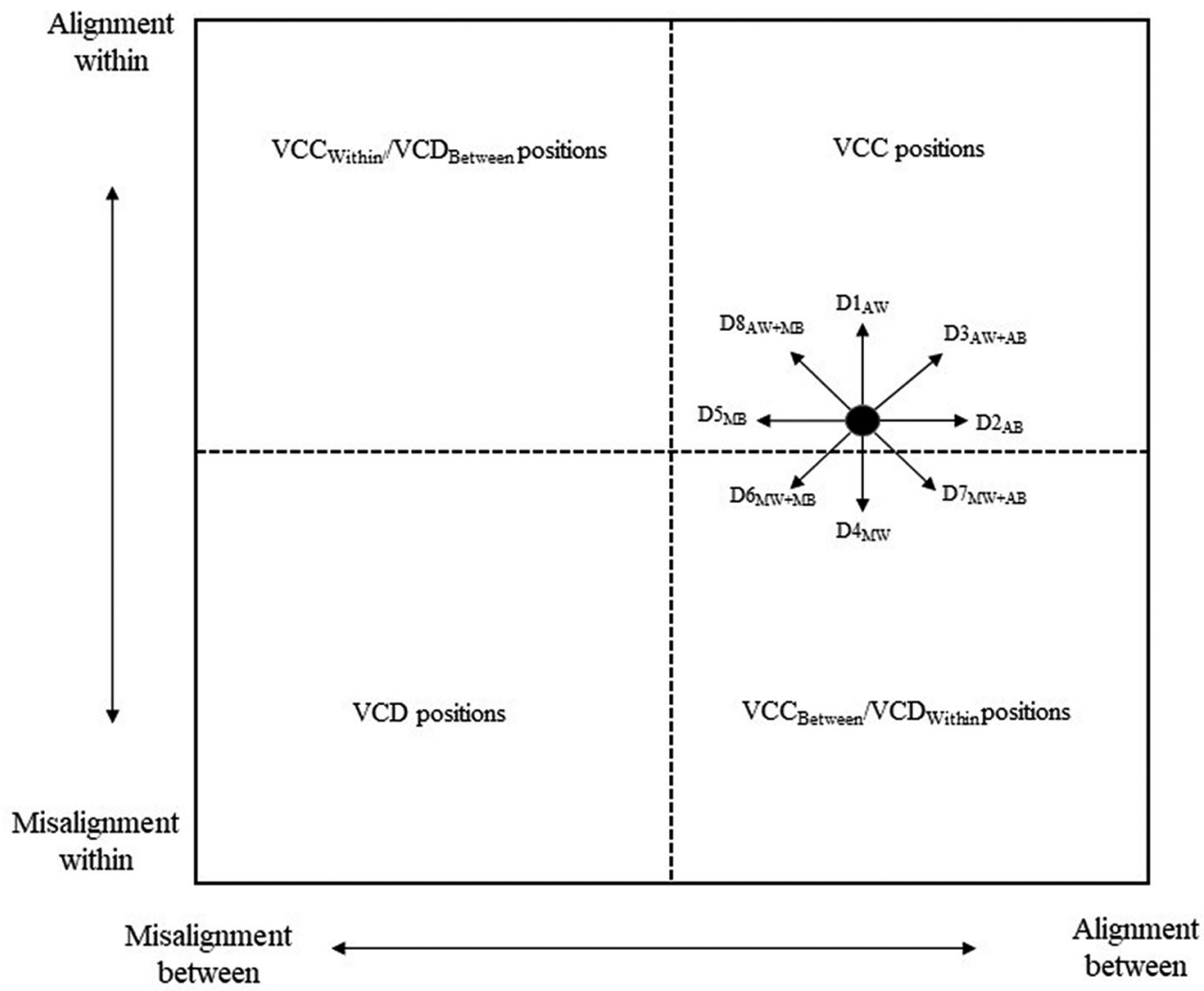

Table 1 Typology of practice element configurations

\begin{tabular}{|c|c|c|c|c|}
\hline $\begin{array}{l}\text { Alignment/misalignment } \\
\text { (of practice elements) }\end{array}$ & Actors & Practice elements & Abbreviations & Description \\
\hline \multirow[t]{3}{*}{ Within elements (AW) } & $\begin{array}{l}\text { Actor A } \\
\text { and }\end{array}$ & Procedures & $P_{A}-P_{B}$ & $\begin{array}{l}\text { Procedures of actor } A \text { is align with procedures of an } \\
\text { actor } B\end{array}$ \\
\hline & Actor B & Understandings & $U_{A}-U_{B}$ & $\begin{array}{l}\text { Understandings of an actor } A \text { is align with } \\
\text { understandings of an actor } B\end{array}$ \\
\hline & & Engagements & $E_{A}-E_{B}$ & $\begin{array}{l}\text { Engagements of an actor } A \text { is align with } \\
\text { engagements of an actor } B\end{array}$ \\
\hline \multirow[t]{6}{*}{ Between elements (AB) } & Actor A (only) & Procedures-Understandings & $P_{A}-U_{A}$ & $\begin{array}{l}\text { Procedures and understandings are aligned at actor } \\
\mathrm{A}^{\prime} \text { side }\end{array}$ \\
\hline & & Procedures-Engagements & $P_{A}-E_{A}$ & $\begin{array}{l}\text { Procedures and engagements are aligned at actor } \\
\text { A's side }\end{array}$ \\
\hline & & Understandings-Engagements & $\mathrm{U}_{\mathrm{A}}-\mathrm{E}_{\mathrm{A}}$ & $\begin{array}{l}\text { Understandings and engagements are aligned on } \\
\text { actor A's side }\end{array}$ \\
\hline & Actor B (only) & Procedures-Understandings & $P_{B}-U_{B}$ & $\begin{array}{l}\text { Procedures and understandings are aligned at actor } \\
\mathrm{B}^{\prime} \text { side }\end{array}$ \\
\hline & & Procedures-Engagements & $P_{B}-E_{B}$ & $\begin{array}{l}\text { Procedures and engagements are aligned at actor } \\
\text { B's side }\end{array}$ \\
\hline & & Understandings-Engagements & $\mathrm{U}_{\mathrm{B}}-\mathrm{E}_{\mathrm{B}}$ & $\begin{array}{l}\text { Understandings and engagements are aligned on } \\
\text { actor B's side }\end{array}$ \\
\hline
\end{tabular}




\section{Methodology}

To explore value co-formation in service ecosystems in more depth using the analytical framework and typologies described previously, qualitative ethnographically-inspired empirical material was used. The methodology behind the empirical material applied a multi-perspective approach to interviews and observations. This approach has been deemed appropriate for the in-depth analysis of service interactions (Arnould, 1998), and for uncovering subtle nuances of dynamic mechanisms' inherent interactions (Miles et al., 2014), as it ultimately provides more in-depth theoretical explanations.

The set of empirical qualitative data consisted of multi-actor data from a special service that transports patients with disabilities to and from a local hospital. Two major service systems are involved, a transport system and a health-care system, integrated by the very transport service. Each of these contains different sub-systems, e.g. administrative systems, technology systems, and information systems, which all deal with the coordination of employees and customers and their respective contexts. The service setting offers a complex and dynamic empirical context suitable for analysing concrete value co-formation processes in service ecosystem contexts.

\section{Data collection}

To gain an in-depth understanding, a wide range of field data was collected. Concrete customer (patients/travellers) travel experiences were compared with the accumulated knowledge of call-centre employees, drivers and health-care professionals. Rich and contextual data allowed flexibility when further exploring the topics arising during the interviews (Miles et al., 2014). Information was gathered from 33 semi-structured interviews; i.e. with 13 customers, 1 personal assistant, 7 drivers, 4 call-centre employees, 2 call-centre managers, 1 receptionist and 5 nurses. Three interviews were conducted during trips and four at customers' homes.

In addition to this, observations were also conducted during seven trips, i.e. five by special taxi, one by a special "route bus" and one by regular bus. During the journeys, field notes, photos and audio recordings were taken, documenting crucial situations and interactions, e.g. interactive behaviours between consumers and drivers, the use of equipment and vehicles, information exchange, etc. Questions arising during the observations were included as a natural part of our interviews with the informants. This approach provided us with their narratives regarding how and why they act as they do. Information was also collected from a collaborative exercise, from a service design session with employees and customers, and from some internal documents.

Using this in situ procedure, contextually- and naturallyoccurring data was collected, data deemed important for gaining an in-depth understanding of the phenomenon (Silverman, 2019). Getting close to the experience of dealing with the service process made the analysis more sensitive with regard to the interpretation of what really matters during value co-formation, including contextual factors such as physical objects, equipment, institutional structures, as well as other resources and practice elements being enacted in the service ecosystems.

\section{Data analysis}

As the empirical data was coded, the empirical categories, themes and variables informing our questions were identified. More to the point, sensitivity to the forms of enactment of the practice elements of the involved actors, during the process, guided our analysis of the data. The constant comparison of the narratives made us sensitive to what was of key importance to the participants.

All the interviews were transcribed. The narratives in each transcript were coded with regard to important or problematic aspects - key in value formation. All these initial empirical codes, which are either in vivo codes or simple descriptive phrases, were then systematically compared and related. During this phase of the coding, the empirical data was coded non-prejudicially, i.e. without a priori coding schemes (Strauss and Corbin, 1998). This systematic procedure resulted in a more limited set of general categories, depicting five recurring situations (points of interaction or "touchpoints"), practices where value forming was shown to be highly crucial. We labelled these "booking", "waiting", "pick-up", "travelling" and "connecting".

In relation to each of these practices, a myriad of narratives were identified showing a complex and rather messy pattern of crucial actor relations, internal and external communications issues, organizational conditions, etc. To further increase the possibility of obtaining credible results, triangulation was used, in the form of different "investigators" that examined the data individually and discussed different interpretations jointly.

Each narrative were then analysed in relation to different practice elements - i.e. procedures, understandings and engagements. Some narratives primarily illustrated configurations whilst others illustrated directions. A few more showed both. It was not difficult to identify instances of alignment and misalignment, within different practice elements in actor-actor or actor-system relations, as well as between different practice elements at each actor side (see the different configurations in Table 1). It was also possible to find instances of the eight value co-formation directions (Table 2 ) in the IVF space (Figure 1) described in the analytical framework (see Literature section). Iterative reflections upon the empirical material in relation to the analytical framework contributed to a deeper understanding of the service ecosystem and illustrated the suggested typologies presented in the article.

\section{Findings}

After a section in which the empirical service systems are briefly commented on, variations in interaction value formation spaces are identified and illustrated. Applying the IVF framework (Echeverri and Skålén, 2021), as a frame for the analysis, made it possible to outline the following two different and interconnected typologies: configurations of practice elements and directions of value formation. Both are described in detail in the section Analytical framework (see Literature review) and illustrated here using empirical quotes. On the empirical level, it is shown that service ecosystems may not be as "eco" as the contemporary marketing literature on service ecosystems assumes. The Findings are structured in the following way: Firstly, a brief description of the empirical case is provided. Secondly, configurations of practice elements are described, 
Table 2 Typology of directions in an IVF space (also graphically depicted in Figure 1)

\begin{tabular}{ll}
\hline General characteristics & Typical directions \\
\hline Value co-creation directions (only) & D1 Aligning within practice elements (D1AW) \\
& D2 Aligning between practice elements (D2AB) \\
Value co-destruction directions (only) & D3 Aligning within and between practice elements (D3AW+AB) \\
& D4 Misaligning within practice elements (D4MW) \\
Mixed cases of value co-creation and value co-destruction directions & D5 Misaligning between practice elements (D5MB) \\
& D6 Misaligning within and between practice elements (D6MW+MB) \\
& D7 Misaligning within but aligning between practice elements (D7MW +AB) \\
& D8 Aligning within but misaligning between practice elements (D8AW + MB)
\end{tabular}

illustrating the complex forms practice elements can take within and between actors. Thirdly, possible directions of value co-formation are described and illustrated by a lengthier quote.

\section{An integrated transport-health-care service}

The empirical case included two relatively separate ecosystems - a transportation ecosystem and a health-care ecosystem - whereby the former aims to transport patients to and from the hospital and the latter aims to take care of the patient. At specific "touchpoints", actors (patients/travellers, doctors, nurses, drivers, booking employees, etc.) interact with other individuals and/or equipment (vehicles, telephones, information technology resources). These interlinked transportation- and health-care services are the context for complex and dynamic value formation processes; an arena for what really matters to the actors involved whether the value is realized or not and for whom.

Five recurring practices were identified as explicitly crucial i.e. booking, waiting, pick-up/drop-off, travelling and connecting, whereby the term "crucial" denotes situations or processes that are experienced as tricky, difficult, causing social friction or just important for value formation. The findings show why this "friction" is a reality and how it is dealt with, both within and between the enacted practice elements.

\section{Configurations of practice elements}

Aligned within and between. On the assumption that the degree of alignment of the practice elements during interactions drives value formation, we are able to identify the following: In cases of value co-creation, the degree of alignment is typically high in all of the above-mentioned relations. Such cases can be positioned in the upper right quadrant of Figure 1. The following quotes illustrate situations where the practice elements of the participants are aligned, both within (marked in the quote using AW) and between (marked using AB). The specific types of practice elements that are aligned are indicated using $\mathrm{P}, \mathrm{U}$ and $\mathrm{E}$ :

We have a good driver, [name of driver], he knows the patients $\left(\mathrm{AW}_{\mathrm{P}}\right)$ and takes the initiative $\left(\mathrm{AB}_{\mathrm{PUE}}\right)$. For example, he stops by and suggests that he can bring someone home $\left(\mathrm{AW}_{\mathrm{E}}\right)$ that he previously brought here $\left(\mathrm{AB} \mathrm{B}_{\mathrm{PU}}\right)$. Then we can prepare them. It's great $\left(\mathrm{AW}_{\mathrm{E}}\right)$ that he takes that initiative[...] She [the driver] picks up patients. Sometimes she has to act like she's in home help, for example helping people to get dressed[...] She often takes the time to go the extra mile $\left(\mathrm{AB}_{\mathrm{PUE}}\right)$ because they [the patients] often appreciate the smallest of efforts $\left(\mathrm{AW}_{\mathrm{UE}}\right)$ very much indeed.(Nurse)

In the quote (see $A W_{P}$ above), the driver's knowledge of what is important to the patients is interpreted as AW the "procedure" element of the participants, and the fact that he takes the initiative (see $\mathrm{AB}_{\mathrm{PUE}}$ ) indicates that he knows what to do and how to do it and that he is committed to doing it, i.e. $\mathrm{AB}$ all the elements on the driver's side. The next marker $\left(\mathrm{AW}_{\mathrm{E}}\right)$ indicates that the driver adheres to a shared element of deep commitment to this service work and that there is an $\mathrm{AB}$ the know-what and know-how (see marker $\mathrm{AB}_{\mathrm{PU}}$ ) in line with the shared view of being committed $\left(A W_{E}\right)$. The expression that the nurse goes the extra mile displays how the practice elements of procedures, understandings and commitment are aligned $\left(\mathrm{AB}_{\mathrm{PUE}}\right)$ and are appreciated by the patients $\left(\mathrm{AW}_{\mathrm{UE}}\right)$.

Misaligned within and misaligned between. However, there are also cases that drive value co-destruction where the degree of alignment is low. The following quotes illustrate situations where practice elements are misaligned both within (MW) and between (MB) the elements (see the lower left corner of Figure 1):

$$
\begin{aligned}
& \text { At some hospitals, it's very difficult to cooperate. It doesn't feel like they } \\
& \text { understand how we operate }\left(\mathrm{MW}_{\mathrm{PU}}\right) \text {. Sometimes, I say they should come } \\
& \text { here and see how things work }\left(\mathrm{MB}_{\mathrm{PU}}\right) \text {. We don't delay customer departures } \\
& \text { just to mess with them as they seem to think }\left(\mathrm{MB} \mathrm{B}_{\mathrm{PE}}\right) \text {, sometimes there isn't a } \\
& \text { vehicle nearby. And it's actually about saving money and then we have to } \\
& \text { coordinate the departures }\left(\mathrm{MW}_{\mathrm{PE}}\right) \text {. Sometimes, it feels like healthcare staff } \\
& \text { don't want to tell the patients }\left(\mathrm{MB}_{\mathrm{UE}}\right) \text {. They say "yes, then you can take it } \\
& \text { up with the patient" (MB }\left(\mathrm{MB}_{\mathrm{UE}}\right) \text {. It can certainly be a matter of both wanting } \\
& \text { patients to leave but not wanting to take the blame }\left(\mathrm{MB}_{\mathrm{PE}}\right) \text { when notifying } \\
& \text { them of a late departure. Sometimes, it's easier to talk to patients than to } \\
& \text { healthcare staff. Sometimes, it doesn't feel like we're working towards the } \\
& \text { same goal (MW } \left.\mathrm{PUE}_{\mathrm{PUE}}\right) \text {. It can sometimes feel like the staff make the decisions } \\
& \text { on behalf of the patient }\left(\mathrm{MB}_{\mathrm{PU}}\right)[\ldots] \text { [... [Name of company] is responsible for } \\
& \text { the transportation side, but the booking staff are the ones with the } \\
& \text { competence to assess }\left(\mathrm{MW}_{\mathrm{U}}\right) \text { what type of transport the patient is in need } \\
& \text { of.(Booking receptionist) }
\end{aligned}
$$

The quote addresses problems of internal collaboration (booking employees vs nurses). The marker $\mathrm{MW}_{\mathrm{PU}}$ indicates that the actors do not have the same knowledge (procedures) and know-how (understandings). The situation also illustrates $\mathrm{MB}$ the nurses' view of booking and how it is actually done by the booking employees $\left(\mathrm{MB}_{\mathrm{PU}}\right)$, emotionally experienced as non-commitment $\left(\mathrm{MB}_{\mathrm{PE}}\right)$. The quote shows that it is a conflict between cost efficiency/planning (booking employees' view of procedure and commitment) and service (nurses' view of procedure and commitment), as shown in the fifth sentence $\left(\mathrm{MW}_{\mathrm{PE}}\right)$ and also indicated by a suspicious attitude regarding limited know-how and commitment among the nurses $\left(\mathrm{MB}_{\mathrm{UE}}\right)$. From the perspective of the booking staff, the nurses are thought of as being reluctant to face customer complaints $\left(\mathrm{MB}_{\mathrm{PE}}\right)$, with the organizational objectives (totally aligned procedures, understandings and engagement, within and between) not being in place $\left(\mathrm{MW}_{\mathrm{PUE}}\right)$ in that the staff decide things without sensitivity and customer know-how ( $\left.\mathrm{MB}_{\mathrm{PU}}\right)$, thus lacking the competence of the booking staff $\left(\mathrm{MW}_{\mathrm{U}}\right)$. In 
other words, the markers in the quote mainly illustrate instances of value co-destruction. The marked elements are misaligned within and between practices; however, it is possible to also identify instances of alignment in the quotes.

Aligned within but misaligned between. However, in many situations, it is possible to find mixed cases, i.e. combinations of alignment and misalignment. In what follows, we illustrate situations where there is AW practice elements - i.e. participants share, to a certain degree, their respective ways of enacting practice elements - but there is MB practice elements $(\mathrm{MB}$ - i.e. either side of the interactive participants does not fully align with the elements in an appropriate way. In the upper left quadrant of Figure 1, we can position such configurations i.e. examples of not only value co-creation (alignment of practice elements within) but also value co-destruction (misalignment of practice elements between):

Oh, special transport! Lately, there's been so much trouble. -Delays to evening pick-ups. (MB $\mathrm{PUE}_{\mathrm{PUE}}$. Almost every day. The people in [location of unit] say one thing and the driver says something completely different $\left(\mathrm{MB}_{\mathrm{PU}}\right)[\ldots]$ From [location of unit], there was a vehicle that broke down, and the driver apologized for the half-hour delay that occurred $\left(\mathrm{AW}_{\mathrm{U}}\right)$.

There have been some "impossible runs", with not enough driving time allowed for distances that are too far $\left(\mathrm{MB}_{\mathrm{PU}}\right)[\ldots]$ The irritation has to be taken out somewhere $\left(\mathrm{AW}_{\mathrm{E}}\right)$, I'm getting paid for it and I think it's better that the patients yell at me than at anyone else, but it feels unfair since we can't do anything (MB $\left.\mathrm{MUE}_{\mathrm{PUE}}\right)$.(Nurse)

In the first quote above (see marker $\mathrm{MB}_{\mathrm{PUE}}$ ), there is $\mathrm{MB}$ most of the practice elements on the production side (booking, driver and planning). All the actors know the aim of the system, but it does not really work as it is supposed to. Conflicting information is given to the customers, illustrating a misfit between the intended information procedure and the actual information ability $\left(\mathrm{MB}_{\mathrm{PU}}\right)$. Actors on both sides know that, in such a situation, it is appropriate to apologize (see $A W_{U}$ ), even if there are limited possibilities of delivering $\left(\mathrm{MB}_{-\mathrm{PU}}\right)$ and people on both sides get irritated $\left(\mathrm{AW}_{\mathrm{E}}\right)$. On the production side, there is no real $\mathrm{AB}$ elements $\left(\mathrm{MB}_{\mathrm{PUE}}\right)$.

Misaligned within but aligned between. Accordingly, there is a configuration of elements where there is MW but AB practice elements. This is a situation whereby each actor, seen separately, enacts procedures, understandings and commitments congruently but does not share this enactment with the other actor, see the following quotes (lower right corner of Figure 1):

You never know how long your doctor's appointment will take, but I always take a chance and book a bus so I can catch that if I have time ( $\left.\mathrm{AB}_{\mathrm{PU}}\right)$. If you haven't booked, you can't just get on, you have to go and book at the front desk and then you might miss it[...] You should be able to book directly with the driver, it's a bit inflexible $\left(\mathrm{MW}_{\mathrm{PU}}\right)$ as it is now. At times, I've seen people waving and wanting to be picked up. If they haven't booked, the driver has to call in and check, and that takes time $\left(\mathrm{AB}_{\mathrm{PUE}}\right)$, the lines to the booking centre can be busy, for example.(Patient)

Someone I was driving could hardly speak English, he was standing there with a note in his hand $\left(\mathrm{MW}_{\mathrm{PU}}\right)$, and I was going to drive him to the emergency room. I had to follow him in $\left(\mathrm{AB}_{\mathrm{PUE}}\right)$, wait, and take a number ticket and show him, using sign language $\left(\mathrm{AB}_{\mathrm{PU}}\right)$, that he had to look out for his number and just sit and wait. It's not like just being a straightforward taxi driver $\left(\mathrm{AB}_{\mathrm{UE}}\right)$. You have to be flexible $\left(\mathrm{AB}_{\mathrm{UE}}\right)[\ldots]$ If something goes wrong, we send in a report. After a whilst, the patients don't have the strength to deal with it whenever something goes wrong $\left(\mathrm{MW}_{\mathrm{PE}}\right)$. There is, for example, one driver who sometimes oversleeps at the weekends $\left(\mathrm{MW}_{\mathrm{PU}}\right)$, but the patient he was driving felt resigned after a whilst and didn't have the strength to say anything anymore $\left(M W_{E}\right)$. "Now they know up there what the problem is, but they don't seem to do anything about it, no point in saying anything about it anymore" $\left(\mathrm{MW}_{\mathrm{PUE}}\right)$.(Driver)

The first quote, from a patient, illustrates a mix of value cocreation and value co-destruction activities. As indicated in the first quote, the know-what $(\mathrm{P})$ and know-how (U), of temporal uncertainty when visiting health care, is used proactively by the patient when booking returns (see marker $\mathrm{AB}_{\mathrm{PU}}$ ). This alignment of elements "between" is combined with the discrepancy with regard to what booking service $(P)$ is and should be (in the customer's view), whilst the indicated rigidity (U) is an MW elements (see MW $\mathrm{PU}$ ). If there is no booking, the normal process violates the assumed ideal and efficient process in which there is $A B$ all the practice elements $\left(A B_{P U E}\right)$. The second quote, not only from a nurse, illustrates a similar discrepancy among the participants regarding what to do and how to do it $\left(\mathrm{MW}_{\mathrm{PU}}\right)$ but also $\mathrm{AB}$ procedure, understanding and commitment on the part of the driver $\left(\mathrm{AB}_{\mathrm{PUE}}\right)$. It is not just a matter of driving the taxi and being flexible $\left(\mathrm{AB}_{\mathrm{UE}}\right)$. The rest of the quote illustrates different instances of MW elements, such as when the patient gives up (no longer committed) complaining about bad (i.e. divergent views on) prescribed service $\left(M W_{\mathrm{PE}}\right)$ or the discrepancy in prescribed service provision and actual know-how, as in the case of oversleeping drivers $\left(\mathrm{MW}_{\mathrm{PU}}\right)$ or the resignation felt over the discrepancy in commitment $\left(\mathrm{MW}_{\mathrm{E}}\right)$ or the production side omitting to deal with the discrepancies (MW $\left.\mathrm{MUE}_{\mathrm{PUE}}\right)$.

\section{Directions of value co-formation}

In the following lengthy quote, the above eight typical directions (Table 1) are identified. Some of them represent value co-creation only (D1-D3), whilst some represent value co-destruction only (D4-D6) and, finally, some illustrate mixed cases (D7-D8). Each direction is specified with regard to the dimensions of the space (see subscripts in Table 1 and Figure 1). For example: $\mathrm{D} 8_{\mathrm{AW}+\mathrm{MB}}$ means that the direction (D8) represents a change towards not only actor AW elements but also actor $\mathrm{MB}$ elements, resulting in a movement towards the upper left "corner" of the space (see arrow D8). In contrast to configurations or positions, all directions are to be viewed as processes in the IVF space:

Much of the travel planning is better when based on the booking staff's experience $\left(\mathrm{D} 22_{\mathrm{AB}}\right)$. They know that some trips with some patients may take longer, and they make adaptations $\left(\mathrm{D} 1_{\mathrm{Aw}}\right)$. Usually, their estimates are based on proven work experience $\left(\mathrm{D}^{\mathrm{AW}}+\mathrm{AB}\right)$ [...] One problem that affects people is the conflict of interest between the booking center and the healthcare staff (D4 $\left.4_{\mathrm{MW}}\right)$. Customers who live very far away can be given an appointment early in the morning $\left(\mathrm{D} 5_{\mathrm{MB}}\right)$. This means that a patient will either have to travel very early in the morning or late at night ( $\left.\mathrm{D} 4_{\mathrm{MW}}\right)$, or that [company name] will send a taxi to pick up a patient all through [county name] (inconvenient/inefficient and lack of competence), which is not costefficient $\left(\mathrm{D} 6_{\mathrm{MW}+\mathrm{MB}}\right)[\ldots]$ The healthcare staff often want to hurriedly get the patients on their way after their appointments to avoid congested waiting rooms and holding up busy staff $\left(\mathrm{D} 7_{\mathrm{MW}+\mathrm{AB}}\right)$. Things can easily go wrong when caregivers have to tell patients they'll have to wait for a number of hours until the next departure, without being able to solve that situation $\left(\mathrm{D} 7_{\mathrm{MW}+\mathrm{AB}}\right)$. There are also cost complications that come with being booked to take a more expensive taxi instead of a regular bus $\left(\mathrm{D} 8_{\mathrm{AW}+\mathrm{MB}}\right)$. (Booking receptionist)

In the very first sentence of the quote, an aligning between elements is indicated in that the know-what and know-how of the booking personnel become more aligned (see arrow D2 $\mathrm{AB}$ in Table 1), in turn, driving value co-creation for all the actors. The next sentence illustrates an adjustment to patients $\left(\mathrm{D} 1_{\mathrm{Aw}}\right)$, i.e. an aligning within practice elements. In the third sentence, aligning both within and between is indicated $\left(\mathrm{D} 3_{\mathrm{AW}+\mathrm{AB}}\right)$. All three enactments illustrate different forms of value co-creation. 
Similarly, there are also cases of value co-destruction. In the sentence, referring to a "conflict of interest", which implicitly drives misaligning within elements $\left(\mathrm{D} 4_{\mathrm{MW}}\right)$, indicate a lack of competence (D5 ${ }_{\mathrm{MB}}$ ) and leading to unpleasant travelling experiences $\left(\mathrm{D} 4_{\mathrm{MW}}\right)$ or a combination of these and nonprescribed cost-ineffective planning ( $\left.\mathrm{D} 6_{\mathrm{MW}+\mathrm{MB}}\right)$.

However, there is also a possibility of finding mixed cases, i.e. combinations of value co-creation and value co-destruction. For example, in the quote, in the sentence referring to a stressful approach, following patient appointments $\left(\mathrm{D} 7_{\mathrm{MW}+\mathrm{AB}}\right)$, health-care staff enact this practice in a slightly inappropriate (decreasing value) but correct and efficient way (increasing value). The final sentence of the quote $\left(\mathrm{D} 8_{\mathrm{Aw}+\mathrm{MB}}\right)$ illustrates the opposite case, whereby the booking is enacted in favour of a convenient but more expensive alternative. An increase in the alignment of the practice elements, even though the actors enact it negatively, is an example of aligning within but misaligning between elements.

\section{Discussion and contribution}

The aim of this article is to identify aspects related to understanding the dynamics of IVF. More to the point, it is to identify possible configurations of practice elements and value formation directions that are assumed to play a crucial role in value formation spaces. Knowledge of this has recently been called for in marketing research (Cabbidu, 2019; Caridá et al., 2019). In this study, an elaborated version of the conceptual IVF framework suggested by Echeverri and Skålén (2021) is applied to a combined transport-health-care service. In the empirical multi-actor study, crucial configurations of the aligning and misaligning of practice elements were identified, capturing two dimensions; i.e. AW and AB. Through this, the IVF framework is tested and validated empirically. More importantly, the article contributes to service and marketing by detailing a conceptualization of a value formation space with the two dimensions, only implicitly indicated in the empirical study of Echeverri and Salomonson (2017) and partly indicated in the IVF framework of Echeverri and Skålén (2021). In relation to these scholars, and the original cocreation and co-destruction studies (Echeverri and Skålén, 2011; Plé and Cáceres, 2010), the article specifically contributes a conceptualization of mixed value co-creation and value co-destruction cases, which is new to value co-formation research in service and marketing.

The article contributes to service and marketing theory in that it suggests two elaborated typologies, i.e. one for practice element configurations and one for value-forming directions, in doing so adding conceptual details to the framework of Echeverri and Skålén (2021), reflecting the core theoretical properties and mechanisms of why and how value is interactively formed. In doing so, it theoretically contributes to IVF research as it has recently been conceptualized by several service and marketing scholars (Caridá et al., 2019; Echeverri and Skålén, 2011; Makkonen and Olkkonen, 2017; Smith, 2013). More specifically, the typology details the mechanisms of the "matching" and "resourcing" processes suggested by Caridá et al. (2019), as well as the social dynamics of resource integration suggested by Cabiddu et al. (2019). In these typologies, service and marketing scholars have tools with which they can empirically identify, measure, assess and depict value formation dynamics in a wide range of service settings, not only in services taking care of vulnerable and disabled customers (Rosenbaum et al., 2017; Echeverri and Salomonson, 2019) as found but also in transformative service research (TSR) (Anderson et al., 2013).

In relation to previous conceptualizations of service ecosystems, the empirical findings of the studied transporthealth-care service indicate the following two things: Firstly, service ecosystems are not necessarily as self-contained as they are imagined to be in the contemporary marketing literature (Vargo and Lusch, 2016) as many of the variations identified in the alignment/misalignment of practice elements, within the crucial practices studied, address substantial interdependencies between ecosystems (transport and health care, in this case). This was shown to lead to unclear responsibilities, a lack of congruent procedures, unnecessary waiting, etc. Secondly, service ecosystems are not so self-adjusting; multiple indications of substantial shortcomings were found in driving schedules, absent internal communications, malfunctioning technical equipment, with the limited coordination of organizational governance aspects clearly driving value codestruction.

In many respects, the two service ecosystems under study do not share institutional arrangements, leading to a lack of or divergence in, policy, organizational objectives and regulations. Further, the findings also show that value is not always cocreated; rather, it is clear that value varies substantially in terms of both value co-creation and value co-destruction and, more importantly, in different combinations. There are numerous dissatisfied disabled patients/travellers, inappropriate activities, misunderstandings, irritations, resistance and conflicts, with the power balance between the actors included being asymmetric in many respects and leading to a lack of consensus regarding the value outcome of the two ecosystems as a whole.

\section{Conclusions and future research}

Using a practice-theory approach, the study elaborates on the notion of the IVF space in a service ecosystem perspective. Two different typologies are suggested, i.e. one outlining how the enactment of different configurations of practice elements is formed and another outlining typical value formation directions in interactive value-formation spaces, uncovering the core theoretical mechanism underpinning why and how value is interactively formed. An empirical case illustrates that many of the crucial aspects of service ecosystems, defining the relative degree of value co-formation, are found in the configurations of specific practices, e.g. during the booking of trips (in the overlap between the individual's personal processes and the transport ecosystem), when waiting (in-between systems whilst actors deal with the link between the phases), when picking up and dropping off (as this relates to the transition between systems, preparations before and after a sequence in-between systems), when travelling (as situated in-between travellers' homes and a second or final destination) and, finally, when connecting (processes that are ongoing during transitioning between one system and another, e.g. being transported from a hospital entrance to a clinic). 
Based on the study, it is possible to outline some practical implications for service and marketing professionals. The suggested value co-formation theory (IVF), implicate the following two things: a focus on interactive value or well-being and this value as co-formed among actors. According to the first implication, value is thought of as intersubjective, contextual and reasonably equally distributed among involved actors. It is thought of as ethically negotiated and extends beyond monetary aspects, e.g. as in the contemporary grand norm of sustainability, with implications for how to do business, service and marketing. In following this, actors need to compromise, to give and take, regarding what kind of value or well-being the service should promote, in relation to different perspectives, as well as the ways to reach a proper distribution of such value or well-being. It is more to it than profit and fairly satisfied customers; business actors most probably need to compromise between short-term and long-term objectives to enact IVF.

The second implication, "co-formation", that specifically is addressed in this article, implicate that actor should try to achieve AW and between practice elements (as well as between different practices), inside own organization and in relation to external customers and other actors. This imply a more equal power balance between actors and more genuine interest among professionals to understand the customers' perspective and for the customer to understand the professional perspective.

If we detail this, it means to revise existing practices so that actors have a reasonably similar view about them, i.e. individuals agree on what knowledge, rules and conditions that need to be in place and enacted on when delivering good quality, conduct and service (for example, regarding professional culture, identity, the policy that professionals should adapt to). As we all know, it is not uncommon for customers to be disappointed with what they get for the money and also professionals facing misbehaving customers. Accordingly, it means to revise existing professional (and customer) skills so that the interacting individuals have reasonably similar views about how to conduct the very practice, i.e. the know-how and actual performance of it (adjusted forms of communication, demeanour, and empathy, etc.) and also, share, the view of how to be engaged, motivated and affected whilst enacting service and marketing interactions. This is the implication of the "within" aspect.

Turning to the "between" aspect of "co-formation", an implication is that each practice element needs to be aligned with other elements. For example, when a professional is serving a customer, he or she is supposed to have and display proper knowledge, as well as a proper experience of how to actually deal skilfully with different crucial situations at hand. If the professionals' engagement is in congruence with both his/ her know-what and know-how, the practice elements are aligned. Accordingly, practice elements also need to be aligned at the customer side as the customer is also involved in the coformation of value, whether the customer is an individual (dyadic service encounter) or a group, organizational unit or other human or non-human actors. In this way, the multiple resources found in the organization and at the customer side, need to be involved and aligned whilst enacting practices to reach the "holy grail" of value in service and marketing contexts, a way of adapting the organizational "machinery" on both sides (between elements) and to each other (within elements).

To this we can add that all practice elements are enacted in material arrangements and/or as physically embodied (mimic, posture, gesture, etc.). The material arrangement also need to be designed in congruence with practice elements to support the very formation of value in interactions. Oftentimes, revision of different aspects of practices may include counterfactual thinking, i.e. to answer the question of if things can be enacted differently and better, in the specific context, to create more intersubjective value. Approaches such as customer involvement for service innovation goes in this direction.

Tentatively, the theoretical framework can (at least in some aspects) be used to explain value formation in situations beyond market-facing organizations. It may be applicable in non-profit marketing, e.g. among non-governmental organizations in their efforts to create value for (and with) clients or to families trying to develop better internal relations and well-being for family members or why not in a dyadic therapeutic conversation, a situation where it is crucial to adjust own perspective to another individual?

Based on surveys, managers can numerically quantify the degree of alignment/misalignment in different organizational contexts and summarize the results in the variables within and between. Configurations can be plotted and different types of directions can be graphically depicted in relation to strength in spaces of $x$ - and $y$-axes. By quantification, scholars and practitioners can plot not just different service ecosystems but also specific organizations, sub-units or departments for comparisons and analyses.

Numerous aspects need to be elaborated upon in future research. It is suggested that future research investigates as follows: how to conceptualize situations where there are different views of what value is; how to conceptualize different processes of alignment/misalignment; how to compare multiactor perspectives when defining value in complex service ecosystems (this may include analysis of non-human actors, such as equipment, environment, materiality, without clear intentionality); how to conceptualize the "eco aspect" of service ecosystems and the "relativeness" of relatively self-contained and self-adjusting ecosystems; how to further validate, empirically, the suggested typologies of the practice element configurations and directions; and how to use the variables in the two typologies to empirically identify (qualitatively) and measure (quantitatively) the type and degree of value coformation in different service contexts. For example, organizations may numerically quantify the degree of alignment/misalignment in relation to all the nine configurations presented in this article (Typology 1). Results from empirical investigations, may be summarized in the variables within elements (one of the dimensions/ $x$-axis) respective between elements (the other dimension/y-axis) without or together with graphically depicted strength of value coformation directions in IVF spaces.

\section{References}

Akaka, M.A., Vargo, S.L. and Lusch, R.F. (2012), "An exploration of networks in value cocreation: a serviceecosystems view", Special Issue - toward a Better 
Understanding of the Role of Value in Markets and Marketing, Emerald Group Publishing Limited, Bingley, pp. 13-50.

Anderson, L., Ostrom, A.L., Corus, C., Fisk, R.P., Gallan, A. S., Giraldo, M. and Williams, J.D. (2013), "Transformative service research: an agenda for the future", fournal of Business Research, Vol. 66 No. 8, pp. 1203-1210.

Archer, M.S. (2003), Structure, Agency and the Internal Conversation, Cambridge University Press, Cambridge.

Archer, M.S. (2007), Making Our Way through the World: Human Reflexivity and Social Mobility, Cambridge University Press, Cambridge.

Arnould, E.J. (1998), "Daring consumer-oriented ethnography", Representing Consumers: Voices, Views and Visions, Routledge, London, pp. 85-126.

Beirão, G., Patrício, L. and Fisk, R.P. (2017), "Value cocreation in service ecosystems", Fournal of Service Management, Vol. 28 No. 2, pp. 227-249.

Cabbidu, F., Moreno, F. and Sebastiano, L. (2019), "Toxic collaborations: co-destroying value in the B2B context", Fournal of Service Research, Vol. 22 No. 3, pp. 241-255.

Camilleri, J. and Neuhofer, B. (2017), "Value co-creation and co-destruction in the airbnb sharing economy", International Fournal of Contemporary Hospitality Management, Vol. 29 No. 9, pp. 2322-2340.

Caridá, A., Edvardsson, B. and Colurcio, M. (2019), "Conceptualizing resource integration as an embedded process: matching, resourcing and valuing", Marketing Theory, Vol. 19 No. 1, pp. 65-84.

Correia, T. (2016), “Doctors' reflexivity in hospital organisations: the nexus between institutional and behavioural dynamics in the sociology of professions", Current Sociology, Vol. 65 No. 7, pp. 1050-1069.

Cova, B., Skålén, P. and Pace, S. (2019), "Interpersonal practice in project marketing: how institutional logics condition and change them", fournal of Business $\mathcal{E}$ Industrial Marketing, Vol. 34 No. 4, pp. 723-734.

Crowther, P. and Donlan, L. (2011), "Value-creation space: the role of events in a service-dominant marketing paradigm", fournal of Marketing Management, Vol. 27 Nos 13/14, pp. 1444-1463.

Daunt, K.L. and Harris, L.C. (2014), "Linking employee and customer misbehaviour: the moderating role of past misdemeanours", fournal of Marketing Management, Vol. 30 Nos 3/4, pp. 221-244.

Echeverri, P. and Salomonson, N. (2017a), "Embodied value co-creation: a turn-taking perspective on service encounter interactions", Fournal of Creating Value, Vol. 3 No. 1, pp. 33-49.

Echeverri, P. and Salomonson, N. (2019), "Consumer vulnerability during mobility service interactions: causes, forms and coping", fournal of Marketing Management, Vol. 35 Nos 3/4, pp. 364-389.

Echeverri, P. and Skålén, P. (2011), "Co-creation and codestruction: a practice-theory based study of interactive value formation", Marketing Theory, Vol. 11 No. 3, pp. 351-373.

Echeverri, P. and Skålén, P. (2021), "Value co-destruction: review and conceptualization of interactive value formation", Marketing Theory, Vol. 21 No. 2, pp. 227-249.
Edvardsson, B., Kleinaltenkamp, M., Tronvoll, B., McHugh, P. and Windahl, C. (2014), "Institutional logics matter when coordinating resource integration", Marketing Theory, Vol. 14 No. 3, pp. 291-309.

Frow, P., McColl-Kennedy, J.R., Payne, A. and Govind, R. (2019), "Service ecosystem well-being: conceptualization and implications for theory and practice", European fournal of Marketing, Vol. 53 No. 12, pp. 2657-2691.

Giraldo, M. (2014), "The dynamics of knowledge co-creation in service encounters: a practice-theoretical approach", Progressive Trends in Knowledge and System-Based Science for Service Innovation, IGI Global, pp. 68-88.

Hasche, N. and Linton, G. (2018), "The value of failed relationships for the development of a medtech start-up", Fournal of Small Business E Entrepreneurship, Vol. 30 No. 1, pp. 97-119.

Hiler, J.L., Cook, L.A. and Northington, W.M. (2018), "Making inconsistent worlds: a conceptual framework for co-competition", fournal of Consumer Marketing, Vol. 35 No. 3, pp. 254-263.

Holbrook, M.B. (2006), "ROSEPEKICECIVECI versus CCV: the resource-operant, skills-exchanging, performanceexperiencing, knowledge-informed, competence-enacting, co-producer-involved, value-emerging, customer-interactive view of marketing versus the concept of customer value: "I can get it for you wholesale", The Service-Dominant Logic of Marketing: Dialog, Debate and Directions, pp. 208-223.

Hughes, T., Vafeas, M. and Hilton, T. (2018), "Resource integration for co-creation between marketing agencies and clients", European fournal of Marketing, Vol. 52 Nos 5/6, pp. 1329-1354.

Korkman, O. and Araujo, L., (2019), "Using practice theory for understanding resource integration in S-D Logic: a multinational study of leading-edge customers", in: Vargo, S.L. and Lusch, R.F. (Eds), The SAGE Handbook of Servicedominant Logic, SAGE, London, pp. 449-465.

Luo, J., Wong, I.A., King, B., Liu, M.T. and Huang, G. (2019), "Co-creation and co-destruction of service quality through customer-to-customer interactions: why prior experience matters", International fournal of Contemporary Hospitality Management, Vol. 31 No. 3, pp. 1309-1329.

McColl-Kennedy, J.R. and Cheung, L. (2018), "Value cocreation: conceptualizations, origins, and developments", in: Vargo, S.L. and Lusch, R.F. (Eds), The SAGE Handbook of Service Dominant Logic, SAGE, London, pp. 63-79.

McColl-Kennedy, J.R., Vargo, S.L., Dagger, T.S., Sweeney, J. C. and Kasteren, Y.V. (2012), "Health care customer value cocreation practice styles", fournal of Service Research, Vol. 15 No. 4, pp. 370-389.

Makkonen, H. and Olkkonen, R. (2017), "Interactive value formation in interorganizational relationships: dynamic interchange between value co-creation, no-creation, and codestruction", Marketing Theory, Vol. 17 No. 4, pp. 517-535.

Miles, M.B., Huberman, A.M. and Saldaña, J. (2014), Qualitative Data Analysis: A Method Sourcebook, SAGE, Thousand Oaks, CA.

Mouzelis, N. (2010), "Self and self-other reflexivity: the apophatic dimension", European fournal of Social Theory, Vol. 13 No. 2, pp. 271-284. 
Ng, I., Maglio, P.P., Spohrer, J. and Wakenshaw, S. (2018), "The study of service: from systems to ecosystems to ecology", The SAGE Handbook of Service-Dominant Logic, pp. 230-240.

Nicolini, D. (2012), Practice Theory, Work, and Organization: An Introduction, Oxford University Press, Oxford.

Plé, L. (2016), "Studying customers' resource integration by service employees in interactional value co-creation", fournal of Services Marketing, Vol. 30 No. 2, pp. 152-164.

Plé, L. and Cáceres, R.C. (2010), "Not always co-creation: introducing interactional co-destruction of value in servicedominant logic", fournal of Services Marketing, Vol. 24 No. 6, pp. 430-437.

Powell, W.W. and Rerup, C. (2017), “Opening the black box: the micro-foundations of institutions", The SAGE Handbook of Organizational Institutionalism, 2nd ed., SAGE Publications, London, pp. 311-337.

Prior, D.D. and Marcos-Cuevas, J. (2016), "Value codestruction in interfirm relationships: the impact of actor engagement styles", Marketing Theory, Vol. 16 No. 4, pp. 533-552.

Reckwitz, A. (2002), "Toward a theory of social practices: a development in culturalist theorizing", European fournal of Social Theory, Vol. 5 No. 2, pp. 243-263.

Rosenbaum, M.S., Seger-Guttmann, T. and Giraldo, M. (2017), "Commentary: vulnerable consumers in service settings", Fournal of Services Marketing, Vol. 31 Nos 4/5, pp. 309-312.

Schatzki, T.R. (2002), The Site of the Social: A Philosophical account of the Constitution of Social Life and Change, Penn State Press, Philadelphia.

Schatzki, T.R. (2019), Social Change in a Material World, Routledge, London.

Schau, H.J., Muñiz, A.M., Jr. and Arnould, E.J. (2009), "How Brand community practices create value", fournal of Marketing, Vol. 73 No. 5, pp. 30-51.

Scott, W.R. (2013), Institutions and Organizations: Ideas, Interests, and Identities, SAGE, London.

Shove, E., Pantzar, M. and Watson, M. (2012), The Dynamics of Social Practice: Everyday Life and How It Changes, SAGE, London.
Silverman, D. (2019), Interpreting Qualitative Data, SAGE Publications Limited.

Skålén, P., Pace, S. and Cova, B. (2015), "Firm-brand community value co-creation as alignment of practices", European fournal of Marketing, Vol. 49 Nos 3/4, pp. 596-620.

Smith, M.A. (2013), "The value co-destruction process: a customer resource perspective", European fournal of Marketing, Vol. 47 Nos 11/12, pp. 1889-1909.

Strauss, A. and Corbin, J. (1998), Basics of Qualitative Research Techniques, SAGE publications, Thousand Oaks, CA.

Suddaby, R., Viale, T. and Gendron, Y. (2016), "Reflexivity: the role of embedded social position and entrepreneurial social skill in processes of field level change", Research in Organizational Behavior, Vol. 36, pp. 225-245.

Teixeira, J.G., Patrício, L., Huang, K., Fisk, R.P., Nóbrega, L. and Constantine, L. (2017), "The minds method: integrating management and interaction design perspectives for service design", fournal of Service Research, Vol. 20 No. 3, pp. 240-258.

Tsiotsou, R.H. (2016), “A service ecosystem experience-based framework for sport marketing”, The Service Industries Fournal, Vol. 36 Nos 11/12, pp. 478-509.

Vafeas, M., Hughes, T. and Hilton, T. (2016), "Antecedents to value diminution: a dyadic perspective", Marketing Theory, Vol. 16 No. 4, pp. 469-491.

Vargo, S.L. (2008), "Customer integration and value creation: paradigmatic traps and perspectives", Fournal of Service Research, Vol. 11 No. 2, pp. 211-215.

Vargo, S.L. and Lusch, R.F. (2016), "Institutions and axioms: an extension and update of service-dominant logic", Fournal of the Academy of Marketing Science, Vol. 44 No. 1, pp. 5-23.

Zainuddin, N., Dent, K. and Tam, L. (2017), "Seek or destroy? Examining value creation and destruction in behaviour maintenance in social marketing", fournal of Marketing Management, Vol. 33 Nos 5/6, pp. 348-374.

\section{Corresponding author}

Per Echeverri can be contacted at: per.echeverri@kau.se 